\title{
Colon cancer of Peutz-Jeghers syndrome with gallolyticus endocarditis
}

\author{
Kiyoshi Miyahara $^{1}$ (D) Shunichi Tobe ${ }^{1} \cdot$ Tatsunori Shizuku $^{1} \cdot$ Rin Inamoto $^{2} \cdot$ Ikuo Katayama $^{3}$
}

Received: 6 September 2019 / Accepted: 3 December 2019 / Published online: 16 December 2019

(c) The Author(s) 2019

\begin{abstract}
We report a case of Peutz-Jeghers syndrome with gallolyticus endocarditis which has not yet been reported. Colon cancer was observed and implicated in Peutz-Jeghers syndrome. A 44-year-old female with fever and heart murmur was diagnosed as infective endocarditis caused by streptococcus gallolyticus. After treatment with antibiotics and mitral valbuloplasty, we performed gastrointestinal endoscopic studies and found polyps in stomach and colon. Histological findings of a large pedunculated colon polyp revealed hamartomatous polyp with a lesion of adenocarcinoma with adenoma. She had pigmentation of digits. Her father had also digits pigmentation and died of pancreas cancer. Peutz-Jeghers syndrome with colon cancer was incidentally diagnosed by infective endocarditis and subsequent colonoscopy.
\end{abstract}

Keywords Peutz-Jeghers syndrome $\cdot$ Colon cancer $\cdot$ Streptococcus gallolyticus $\cdot$ Infective endocarditis

\section{Abbreviations \\ PJS Peutz-Jeghers syndrome \\ STK11 Serine/threonine kinase-11}

\section{Introduction}

Peutz-Jeghers syndrome (PJS) is an autosomal dominant inherited disorder with germline mutation in serine/threonine kinase-11 (STK11) gene and characterized by intestinal hamartomatous polyps with skin melanocytes macules. The estimated incidence of the disease is approximately 1 in 50,000-200,000 births [1]. The clinical symptoms are non-specific such as anemia, nausea, abdominal pain and intestinal intussusception. Accordingly, it is hard to come to a diagnosis without gastrointestinal endoscopic study. Patients with PJS have an increased risk of cancer in colon, pancreas, lung, breast and ovary [2, 3].

Kiyoshi Miyahara

kiyoshi.miyahala@tokushukai.jp

1 Department of General Internal Medicine, Shonan Fujisawa Tokushukai Hospital, Tujido-Kandai 1-5-1, Fujisawa, Kanagawa, Japan

2 Center of Hepato-Gastroenterology, Shonan Fujisawa Tokushukai Hospital, Fujisawa, Kanagawa, Japan

3 Department of Cardiovascular Surgery, Shonan Fujisawa Tokushukai Hospital, Fujisawa, Kanagawa, Japan
Infective endocarditis is a potentially lethal disease and the incidence is from 1.5 to 11.6 cases per 100,000 people [4]. $7 \%$ of all kinds of infective endocarditis are caused by Streptococcus gallolyticus [5]. Gallolyticus endocarditis is well recognized to be accompanied by colon cancer and endoscopic study of colon has been recommended [6].

We recently encountered an adult case of Peutz-Jeghers type hamartoma with colon cancer associated with gallolyticus endocarditis.

\section{Case report}

A 44-year-old female with a recent onset of night chills and fever was referred to our hospital and diagnosed as infective endocarditis because of mitral regurgitation on auscultation and mitral valve vegetation on transthoracic echocardiography (Fig. 1). Laboratory values included total protein level of $7.0 \mathrm{~g} / \mathrm{dl}, \mathrm{C}$-reactive protein level of $5.39 \mathrm{mg} / \mathrm{dl}$, erythrocyte sedimentation rate of $45 \mathrm{~mm} / \mathrm{h}$, white-cell count of $4700 / \mu \mathrm{l}$ with $85.2 \%$ neutrophils, hemoglobin level of $9.6 \mathrm{~g} /$ $\mathrm{dl}$, mean corpuscular volume of $73.6 \mathrm{fl}$, reticulocyte count of $30,900 / \mu \mathrm{l}$, iron level of $12 \mu \mathrm{g} / \mathrm{dl}$, ferritin level of $55.0 \mathrm{ng} /$ $\mathrm{ml}$ and platelet count of $161,000 / \mu \mathrm{l}$. She was admitted to our hospital and received intravenous medication of ceftriaxone and vancomycin. S. gallolyticus was identified in blood culture. Physical examination revealed neither Janeway lesions nor Osler nodes. Skin pigmentation of bilateral fingers and 


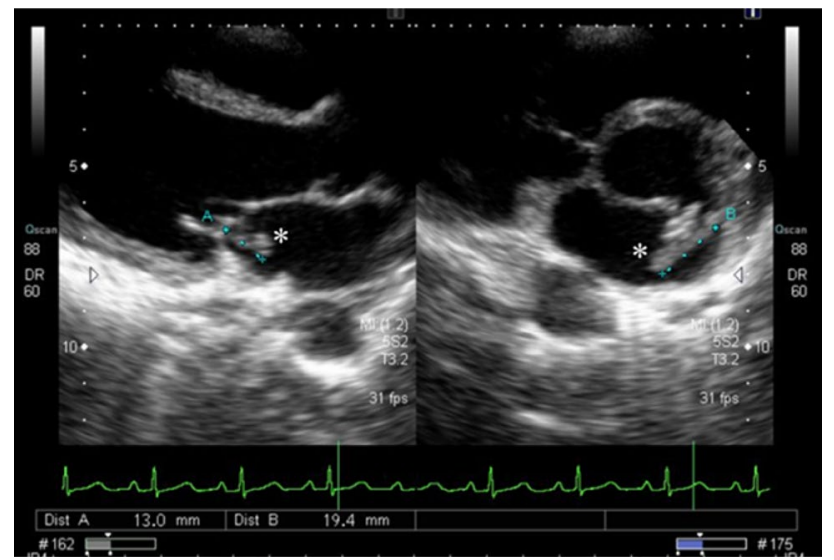

Fig. 1 Transthoracic echocardiogram. Left image is long-axis tomogram and right image is short-axis tomogram. There is a large soft vegetation (astreik) on mitral valve

soles had existed without pain since childhood. Pigmentation of buccal mucosa was visible but that of lips was not (Fig. 2).

Two days later, after transfusion of eight units of red cell concentrate, mitral valvuloplasty was performed successfully by cardiovascular surgeons. Microscopic findings of resected mitral valve showed bacterial colonization on the surface of thrombus. Three weeks later, ceftriaxone was discontinued due to adverse effects and ampicillin had been administered intravenously for six consecutive weeks.

Colonoscopy was performed on 36th hospital day because it had been reported that colon cancer is frequently associated with gallolyticus endocarditis, and revealed a pedunculated polyp in the splenic flexure of colon (Fig. 3). The large polyp with $30 \mathrm{~mm}$ in length was retrieved by endoscopic polypectomy and its pathological diagnosis was hamartomatous polyp with a lesion of adenocarcinoma with adenoma (Fig. 4). Laboratory data showed total protein level of $6.7 \mathrm{~g} /$ $\mathrm{dl}, \mathrm{C}$-reactive protein level of $0.27 \mathrm{mg} / \mathrm{dl}$, white-cell count of $2100 / \mu \mathrm{l}$ with $45.6 \%$ neutrophils, hemoglobin level of $10.8 \mathrm{~g} /$ $\mathrm{dl}$, mean corpuscular volume of $84.3 \mathrm{fl}$ and platelet count of

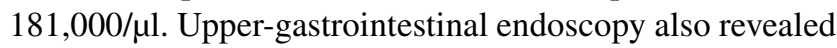
multiple polyps with $2-15 \mathrm{~mm}$ in diameter in the body of stomach. Endoscopically, twelve polyps sized less than $6 \mathrm{~mm}$ in diameter appeared as translucent, smooth-surfaced sessile polyps. There were three larger subpedunculated polyps with $10 \mathrm{~mm}, 12 \mathrm{~mm}$ and $15 \mathrm{~mm}$ in diameter. Endoscopic mucosal resections were performed for these three polyps, all of which were pathologically diagnosed as fundic gland polyps. We performed balloon-assisted endoscopies by oral and anal insertion to survey whole small intestine and found no polyp in duodenum, jejunum and ileum.

Her father died of pancreas cancer at age 57 . He also had pigmentation of digits without a medical history of gastrointestinal disease. Her elder brother also had the same kind
Fig. 2 Skin melanocytes macules of hands and feet, and pigmentation of buccal mucosa. a Disseminated pigmentation in various size is visible on the right fingers. b Skin pigmentation on the toes and sole of the left foot. c Melanotic pigmentation of right buccal mucosa is visible. d No pigmentation on lips
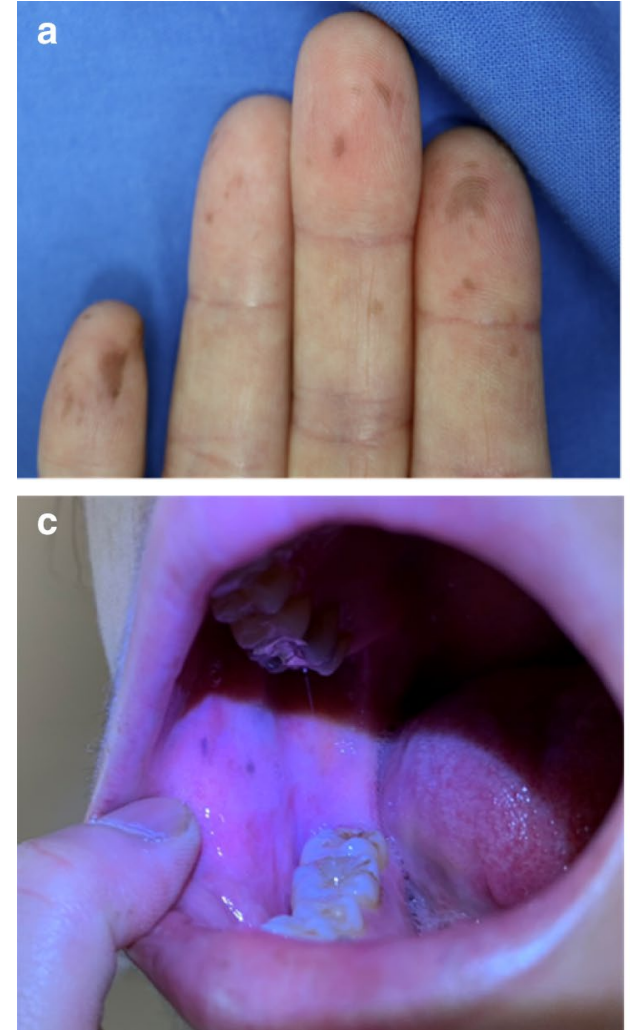
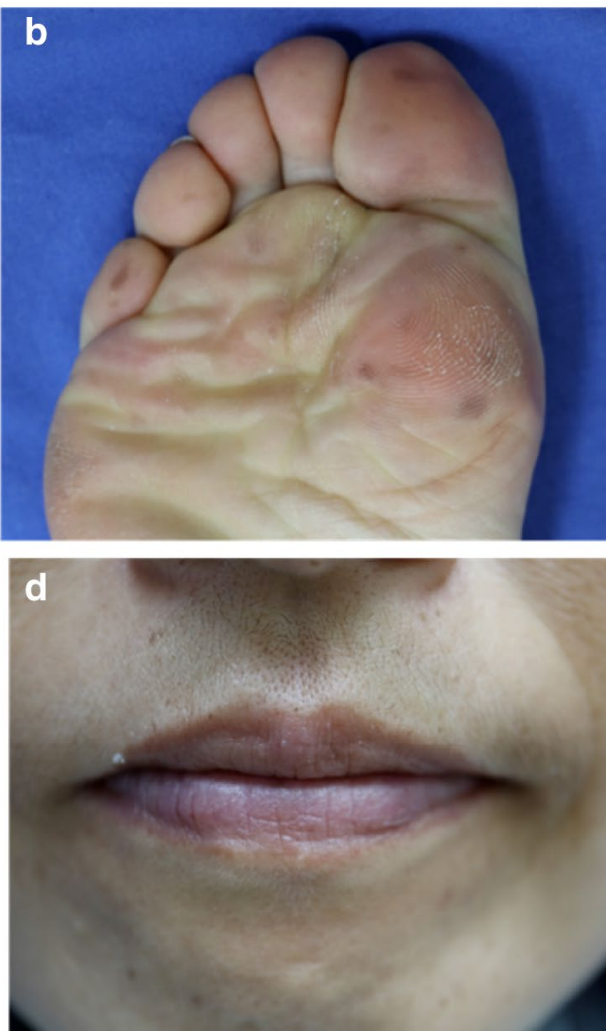

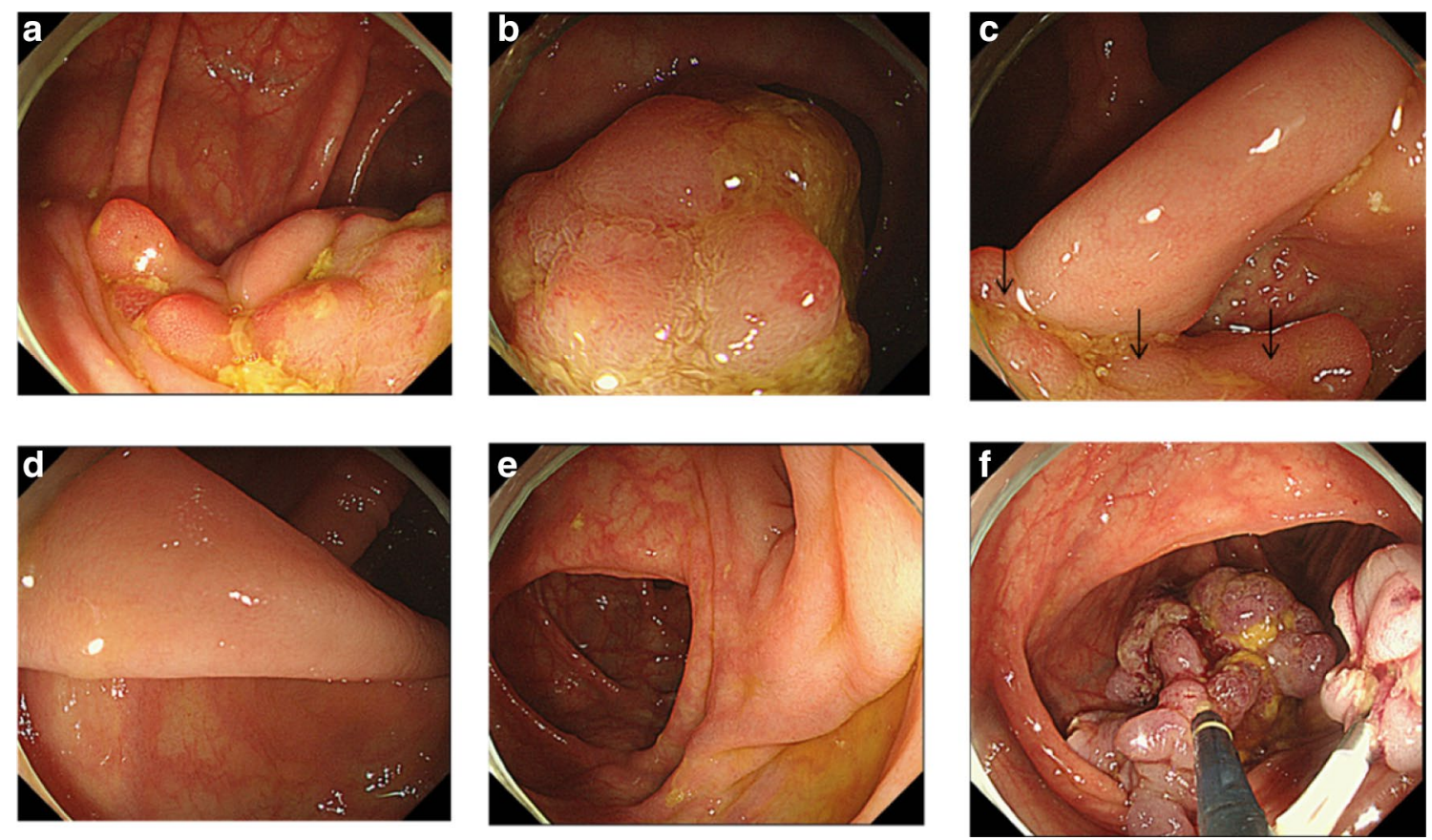

Fig. 3 Colonoscopic findings of the large pedunculated colon polyp in the splenic flexure of colon. $\mathbf{a}, \mathbf{b}$ Views of a part of polyp head. c The polyp neck and arrows show the part of polyp head. d The long stalk of pedunculated polyp. e The root of pedunculated polyp.

of skin pigmentation but had had no health problem up to that time.

Since the patient had a colon hamartomatous polyp with the characteristic pigmentation of buccal mucosa and skin, she was diagnosed as PJS according to the diagnostic criteria of European consensus statement [3]. According to her memories, perioral pigmentation had faded away with growth. We recommended that she should receive genetic testing for mutations in the STK11 gene, but she did not want it. She was in good physical condition on discharge, with laboratory values including total protein level of $7.0 \mathrm{~g} /$ $\mathrm{dl}, \mathrm{C}$-reactive protein level of $0.17 \mathrm{mg} / \mathrm{dl}$, white-cell count of $2100 / \mu \mathrm{l}$ with $48.7 \%$ neutrophils and hemoglobin level of $11.6 \mathrm{~g} / \mathrm{dl}$.

\section{Discussion}

In the case presented here, PJS and gallolyticus endocarditis coexisted, which has not been reported before. This 44-yearold female patient had colon cancer in addition to the above syndrome and disorder.

Infective endocarditis is a relatively rare but life-threating disease with acute heart failure due to valve destruction and organ failure of brain and kidney. There are many causative bacteria inducing infective endocarditis. S. gallolyticus accounts for $7 \%$ of them [5]. The first case of enterococcal f A view of the polyp head on the process of retrieving just after polypectomy. Small parts of the head were torn off during operation and stayed on the right side of the view

endocarditis associated with colon cancer was reported in 1951 [7] and gallolyticus endocarditis is nowadays well known as a high risk of colon cancer [8]. S. gallolyticus is one of intestinal colonized bacteria. Recently, relationships between intestinal bacteria and colorectal cancer have been indicated in Fusobacterium, Peptostreptococcus, Atopobium and Actinomyces by metagenomics and metabolic analysis [9]. Currently, it is not certain in this case whether intestinal colonized S. gallolyticus is an additive inducer of carcinogenesis or not.

Bacteremia due to other intestinal microbes also has a high risk of colon cancer [10]. It is speculated that these bacteria enter the bloodstream with intestinal dysbiosis and perturbed barrier function. The nature and the etiological role of $S$. gallolyticus with colon neoplasm have been extensively studied in mice. It is suggested that $S$. gallolyticus might be passengers and cancer-promoting bacteria [11]. The underlying mechanisms remain to be clarified further.

In this patient, a large colon polyp was found on endoscopic screening for colon cancer and was histopathologically diagnosed as a colon hamartomatous polyp. Hamartomatous polyposis syndromes are rare genetic syndromes, which include PJS, PTEN hamartoma tumor syndrome (Cowden Syndrome and Bannayan-Riley-Ruvalcaba Syndrome) and Juvenile polyposis syndrome. PJS can be differentiated from Cowden syndrome which has mucocutaneous lesions including trichilemmomas, acral keratoses and 

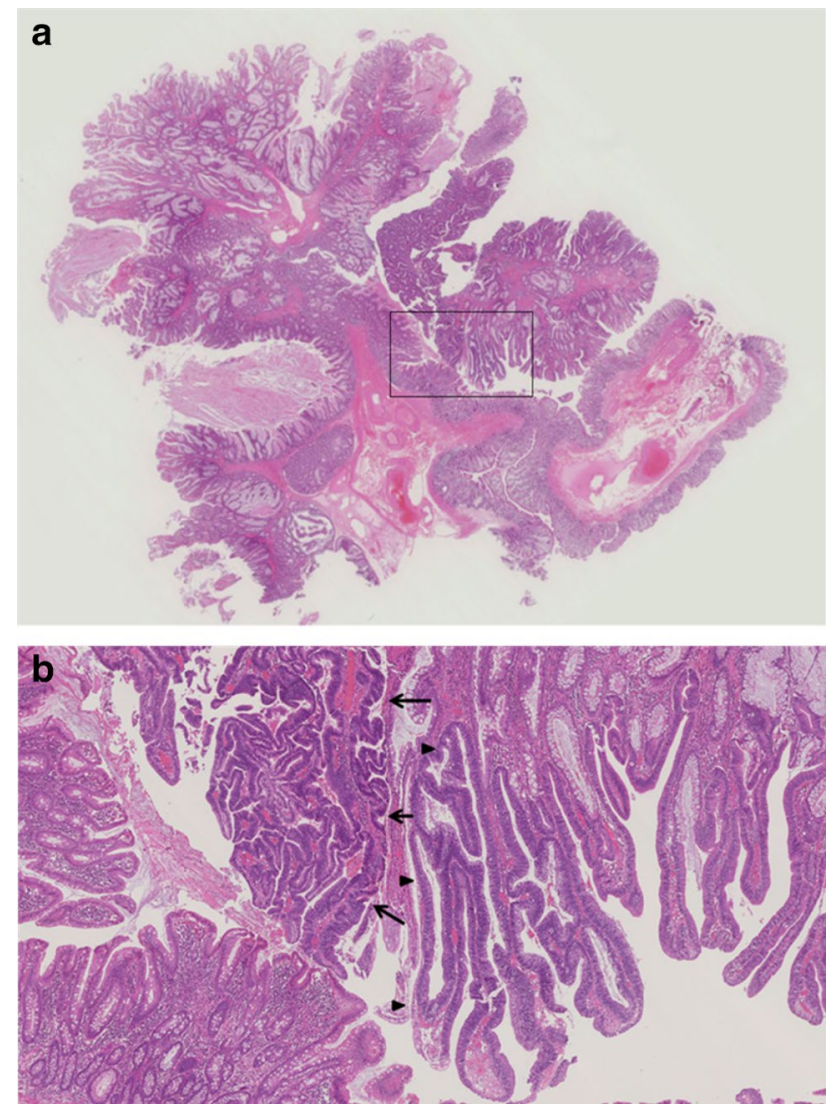

Fig. 4 Histopathological findings of the colon polyp. a Low power magnification of the hamartomatous polyp of colon. b Enlarged boxed section of figure a. Hamartomatous polyp with a lesion of adenocarcinoma (arrows) with villous adenoma (arrowheads) ( $\mathrm{H}$ and $\mathrm{E}$ stain)

papillomatous lesions, and from Bannayan-Riley Ruvalcaba syndrome which has macrocephaly, lipomatosis and pigmented macules of the glans penis. Pigmented spots in Cowden and Bannayan-Riley-Ruvalcaba syndrome characteristically do not occur on the lips as seen in PJS. Juvenile polyposis syndrome is characterized by multiple gastrointestinal juvenile polyps but is not associated with mucocutaneous pigmentation.

PJS is a rare autosomal dominant disorder characterized by the hamartomatous polyps in the gastrointestinal tract and by melanin spots on lips, buccal mucosa and digits. Germline mutations of the STK11 gene, located on chromosome 19p13.3, are the cause in the majority of cases with PJS [12, 13]. STK11 is a protein kinase regulating energy metabolism and proliferation of the cell and is recognized as a key enzyme of tumor suppression $[14,15]$.

STK11 deficiency in the gastrointestinal stroma is an important factor for the formation of polyps [16, 17], but the trigger of its mechanisms has remained unclear. Recently, a new finding has been reported; the mutations of STK11 in T cells induce inflammation in the stroma and drive polyp formation [18]. Genetic alterations of STK11 were also found to play a causal role in lung adenocarcinoma [19]. It was suggested that an overlapping of p53 mutation might increase carcinogenesis [20]. Cancer risk in PJS is high with age. The risk for developing cancer at the age of $30,40,50$ and 60 years is $3-5 \%, 17-21 \%$, $31-47 \%$ and $55-60 \%$, respectively. Gastrointestinal cancer is the most common cancer and the risk is $28-33 \%$ at age $60[21,22]$. Because of increased cancer risk in gastrointestinal tract, pancreas, breast and ovary, it has been recommended that patients with PJS be periodically followed to rule out cancers [1-3].

We speculated the reason that coexistence of PJS and gallolyticus endocarditis has not been reported is due to very low prevalence of each disorder in the population [1, 4]. Consequently, an extremely rare chance of their coexistence might have incidentally occurred. Additionally, most patients with PJS had undergone preventive resections of intestinal polyps in their younger ages than this patient after diagnosis of PJS [2, 3], which might have resulted in less opportunities of intestinal microbial entry into the bloodstream and subsequent infective endocarditis. The age of diagnosis of PJS is between 10 and 30 years with the average age of 26 years in women [23]. On the contrary, the skin pigmentation, only visible sign of PJS in this patient, had not been concerned by anyone until 44 years of age and resulted in the delay of its diagnosis. As the consequence, at the middle age with higher risk of colon cancer, it was observed that PJS and gallolyticus endocarditis coexisted in this patient. Therefore, it would be likely that there have been no literatures regarding their coexistence.

In summary, most patients with PJS are found in children with its clinical features such as pigmentation of lips and a family history of PJS. Pigmentation of lips usually fades away after adolescence. Accordingly, for the diagnosis of PJS in adult case, clinical signs and symptoms which lead to examine gastrointestinal tract are important clues to find hamartomatous polyps. In this case, gallolyticus endocarditis might have been a silent sign of PJS.

Acknowledgements We would like to express our deep gratitude to Dr. Osamu Tokunaga, Shonan Fujisawa Tokushukai Hospital and Dr. Hisashi Oshiro, Jichi Medical University Hospital, for their great contributions to make the pathological pictures and diagnosis.

\section{Compliance with ethical standards}

Conflict of interest Kiyoshi Miyahara, Shunichi Tobe, Tatsunori Shizuku, Rin Inamoto and Ikuo Katayama declare that they have no conflict of interest. 
Human and animal rights All procedures followed have been performed in accordance with the ethical standards laid down in the 1964 Declaration of Helsinki and its later amendments.

Informed consent Informed consent was obtained from all patients for being included in the study.

Open Access This article is licensed under a Creative Commons Attribution 4.0 International License, which permits use, sharing, adaptation, distribution and reproduction in any medium or format, as long as you give appropriate credit to the original author(s) and the source, provide a link to the Creative Commons licence, and indicate if changes were made. The images or other third party material in this article are included in the article's Creative Commons licence, unless indicated otherwise in a credit line to the material. If material is not included in the article's Creative Commons licence and your intended use is not permitted by statutory regulation or exceeds the permitted use, you will need to obtain permission directly from the copyright holder. To view a copy of this licence, visit http://creativecommons.org/licenses/by/4.0/.

\section{References}

1. Giardiello FM, Trimbath JD. Peutz-Jeghers syndrome and management recommendations. Clin Gastroenterol Hepatol. 2006;4:408-15.

2. van Lier MGF, Wagner A, Mathus-Vliegen EMH, et al. High cancer risk in Peutz-Jeghers syndrome: a systematic review and surveillance recommendations. Am J Gastroenterol. 2010;105:1258-64.

3. Beggs AD, Latchford AR, Vasen HFA, et al. Peutz-Jeghers syndrome: a systematic review and recommendations for management. Gut. 2010;59:975-86.

4. Bin Abdulhak AA, Baddour LM, Erwin PJ, et al. Global and regional burden of infective endocarditis, 1990-2010: a systematic review of the literature. Glob Heart. 2014;9:131-43.

5. Murdoch DR, Corey GR, Hoen B, et al. Clinical presentation, etiology and outcome of infective endocarditis in the 21st century: the international collaboration on endocarditis-prospective cohort study. Arch Intern Med. 2009;169:463-73.

6. Beeching NJ, Christmas TI, Ellis-Pegler RB, et al. Streptococcus bovis bacteraemia requires rigorous exclusion of colonic neoplasia and endocarditis. Q J Med. 1985;56:439-50.

7. McCoy WC, Mason JM 3rd. Enterococcal endocarditis associated with carcinoma of the sigmoid: report of case. J Med Assoc State Ala. 1951;21:162-6.

8. Gupta A, Madani R, Mukhtar H. Streptococcus bovis endocarditis, a silent sign for colonic tumour. Colorectal Dis. 2010;12:164-71.

9. Yachida S, Mizutani S, Shiroma H, et al. Metagenomic and metabolomic analyses reveal distinct stage-specific phenotypes of the gut microbiota in colorectal cancer. Nat Med. 2019;25:968-76.
10. Kwong TNY, Wang X, Nakatsu G, et al. Association between bacteremia from specific microbes and subsequent diagnosis of colorectal cancer. Gastroenterology. 2018;155:383-90.

11. Pasquereau-Kotula E, Martins M, Aymeric L, et al. Significance of Streptococcus gallolyticus subsp. gallolyticus association with colorectal cancer. Front Microbiol. 2018. https://doi.org/10.3389/ fmicb.2018.00614.

12. Hemminki A, Markie D, Tomlinson I, et al. A serine/threonine kinase gene defective in Peutz-Jeghers syndrome. Nature. 1998;391:184-7.

13. Jenne DE, Reimann H, Nezu J, et al. Peutz-Jeghers syndrome is caused by mutations in a novel serine threonine kinase. Nat Genet. 1998;18:38-43.

14. Shaw RJ, Kosmatka M, Bardeesy N, et al. The tumor suppressor LKB1 kinase directly activates AMP-activated kinase and regulates apoptosis in response to energy stress. Proc Natl Acad Sci USA. 2004;101:3329-35.

15. Fan D, Ma C, Zhang $\mathrm{H}$. The molecular mechanisms that underlie the tumor suppressor function of LKB1. Acta Biochim Biophys Sin (Shanghai). 2009;41:97-107.

16. Katajisto P, Vaahtomeri K, Ekman N, et al. LKB1 signaling in mesenchymal cells required for suppression of gastrointestinal polyposis. Nat Genet. 2008;40:455-9.

17. Korsse SE, Biermann K, Offerhaus GJA, et al. Identification of molecular alterations in gastrointestinal carcinomas and dysplastic hamartomas in Peutz-Jeghers syndrome. Carcinogenesis. 2013;34:1611-9.

18. Poffenberger MC, Metcalfe-Roach A, Aguilar E, et al. LKB1 deficiency in $\mathrm{T}$ cells promotes the development of gastrointestinal polyposis. Science. 2018;361:406-11.

19. Sanchez-Cespedes M, Parrella P, Esteller M, et al. Inactivation of LKB1/STK11 is a common event in adenocarcinomas of the lung. Cancer Res. 2002;62:3659-62.

20. Wei C, Amos CI, Stephens LC, et al. Mutation of Lkb1 and p53 genes exert a cooperative effect on tumorigenesis. Cancer Res. 2005;65:11297-303.

21. Hearle N, Schumacher V, Menko FH, et al. Frequency and spectrum of cancers in the Peutz-Jeghers syndrome. Clin Cancer Res. 2006;12:3209-15.

22. Chen HY, Jin XW, Li BR, et al. Cancer risk in patients with PeutzJeghers syndrome: a retrospective cohort study of 336 cases. Tumour Biol. 2017. https://doi.org/10.1177/1010428317705131.

23. Utsunomiya J, Gocho H, Miyanaga T, et al. Peutz-Jeghers syndrome: its natural course and management. Johns Hopkins Med J. 1975;136:71-82.

Publisher's Note Springer Nature remains neutral with regard to jurisdictional claims in published maps and institutional affiliations. 